occasioned by; the contraction of the ven- six hours, did not in any measure arrest the tricle. Space will not allow me, at present, spreading of the mortification, which had to go further into the proofs; but, if the now involved an inch and half in circumfesubject be not taken up by some more com- rence of the.left cheek and upper lip, and petent person, I may, at a future period, re- extended downwards under the chin. The turn to its consideration.

33, Trinity College, Dublin ; May 10, 1831.

\title{
TALIACOTIAN OPERATION
}

FOR RESTORATION OF THE UNDER IIP.

\section{By C. Bryce, M.D.*}

Iv July last the Hakim-Bashi sent me, at Constantinople, the following singular case of destruction by mortification of the under lip and chin, which, from the success following the treatment, seems worthy of notice.

The subject of it, a Turkish child three years old, was attacked in June preceding with scarlet-fever, that spread sparingly over the body, and in which the mouth and throat were aphthous but not ulcerated, disappearing by the use of a wine-gargle and laxatives. The subsequent affection of the mouth was preceded by much fever and restlessness, and appeared in a small pustule on the left commissure of the mouth, which became rapidly black, and opened, discharging an offensive sanies; the gums at the same time were discoloured, and bled on the child's crying. The sore formed on outside of mouth spread quickly downward and laterally; and on the seventh day of the disease, when the patient was first brought to me, the whole of the under lip aud chin presented a foetid, black, irregularshaped slough, surrounded by a broad darkcoloured line of inflammation, marking the threatened progress of the disease on the integuments, the left cleek, and upper lip, which were painful and hard. The incisors of the lower jaw were loose, their gums and alveoli partaking of the affection, and by contact involving the tip and anterior edges of the tongue. The tongue was cedematous and loaded, but the fauces showed no ap. pearance of unhealthiness. The countenance had a peculiar livid colour; body dry and hot; pulse small and rapid; diarrboea. From certain circumstances, an emollient poultice to the sore, and frequent ablutions of the mouth, and a few drops of laudanum internally, were all that could be recommended at this period. On the third day's visit, and tenth of the disease, observing the rapid progressive destruction of the in teguments, the gangrenous parts were touched with diluted nitric acid, and sulphate of quinia with opium was exhibited. This external treatment, twice repeated in thirty.

* Glasgow Medical Jourmal, May. diarrbca was checked, and the child had enjoyed some hours of sleep, but was evidently sinking. It was now determined on to apply a fermenting poultice over- the diseased parts, and to administer pills composed of quinine, camphor, and hyosciamus, in large doses, and allow eight ounces of English porter daily. This plan, after fortyeight hours' continuance, showed a marked improvement in the patient; the mortification had made no farther progress for the last eighteen hours; the slough was partially detached; whilst the look of the child was improved, with a slower and fuller pulse. The poultice and porter were continued as before, as were the pills, reduced in strengtb. In a few days the slough was totally separated, leaving a florid granulating surface. The integuments had assumed their natural colour and feel; four incisors and two canine teeth, with fragments of alveoli, were removed, as were also three small exfoliations from the under maxillary bone; the tongue had thrown off its slough, and appeared healthy.

The only treatment practicable for the moment, was to encourage granulations by spirituous applicatious, and support and di. minish the loss of substance by compresses and bandages, whilst the general bealth of the child was improved by liberal diet and change of air. In six weeks a healthy cicatrix had formed, and the breach of continuity was much lessened by its contractions. It was now very evident that a complete, or even partial, reparation of the great destruction of the soft parts could be promised only by an operation, the necessity for which arose as much from the disagreeable deformity of the face as from the evident ill-effects on the system that the constant flow of saliva occasioned. The writer was encouraged to this attempt by the very perfect success of a Taliacotian nose, made a short time before by bim at Constantinople. The operation, in which he was assisted by the advice and skill of his intelligent friend Mr. Millingen, was performed by removing from the upper part of the throat a triangular portion of integuments, whose suitable form and size had been judged of by measuring a model of the lip and chin adapted to the deficiency. This segment was now reflected, the twist being made immediately on the point of the chin, and its two angular points attached by ligatures to the commissures of the mouth, previously made bare by scarifications, as was also the whole of the former cicatrised surface. The flap was further supported by 
athesive plaster and bandage, and the Found on the throat brought together by the same means. 'The parents were directed to keep the ehild in a recumbint posture, and to feed ber sparingly on pap. The wound was looked at on the third day; on the fifth the dressings were changed, when adhesion had taken place on one side very completely, and, on the other, although the ligatures had cut through, there was no opening of the wound; there existed no symptoms of excessive inflammation of the parts, or of irritation of the system. In fifteen days the cicatrices were perfectly formed, and the wound on the throat almost closed. On closing the mouth the artificial lip seemed very well adapted to the other, and even when partially open retained the saliva, and very materially diminished the unseemliness of features. It cannot be yet determined whether or not the second set of teeth, with their alveoli, have been so much destroyed as to prevent the great held derivable from their growth, by supporting the flaccid flap. On the whole, the result of the operation was very satisfactory, especially at Constantinople, by exalting the practice and utility of surgery amongst the Furks, and encouraging them to submit to operations beyond the barber's province of bleeding and tooth-drawing.

Glasgow, 12th A pril, 1831.

\section{ANNUAL REPORT}

OF THE

\section{MEDICAL SCHOOL}

OF THE

\section{UNIVERSITY OF LONDON,}

On the occasion of the distribution of the Medals and Certificates of Honours to the Students on the "21st of May, 1831.

\section{By Propesson DAVIS.}

\section{Sir Tromas Dexuran in the Chair.}

Mr. Chairmas,--In compliance with the wishes of the Council, and in conformity with the practice of preceding years, the Professors of the School of Medicine in this University have the honour, at the conclusion of their third annual session, to submit to the proprietors and other gentlemen prezent, a slicrt accunt of the progress and prospects of the department of the institution $\mathrm{x}$ hich is more immediately under their chatge.

It is, Sir, a matter of extreme regret to your professors of this school, that in one of its most important classes, certain irregularities and disturbances bave occurred during the session now closing, which have not a little contributed to impair its utility, and to iujure its reputation. But, Sir, it is not within the province of the individual who has now the honour of addressing you, eren to give an opinion on any of the malters in dispute, much less to enter into any details on questions which are at this moment in the conrse of being discussed, and, also, he earnestly hopes, of being speedily, happily, and satisfactorily, adjusted.

In all the other classes of the medical school of the University, your professors have much pleasure in reporting that there has been the most perfect order throughout the session. The business of the present meeting will, indeed, soon prove to you, that many of our students, during their late sessional attendance in the schools, have honourably distinguished themselves by an assiduous and most successful prosecution of their professional studies; whilst of the great majority, -as well of those who have not contended for the honours of this day, as of those who have contended for them unsuccessfully, -it is a fact well known to their respective professors, that manyso many, indeed, as to constitute by far the greater number of the entire school,have made highly-important accessions to their previous knowledge.

In favour of those few who, whilst possessing sufficient share, both of industry and natural ability, have nevertheless failed to acquit themselves fully to the satisfaction of their teachers, there are two or three circumstances which deserve to be particularly noticed, and which cannot be too frequently repeated on occasions like the present.

Of these, the one probably of greatest influence is, that too many of our youths, by reason of want of knowledge, or at least of sound discretion on the part of their friends, are introduced into the business department of our profession, without a sufficient previous education to enable them to prosecute with advantage the studies which await them on their future medical schools.

The result of this ill advised procedure is, that the subjects of it are brought suddenly to encounter the greatest difficulties incident to the prosecution of abstruse professional 